\title{
Regions of the Genome that Affect Agronomic Performance in Two-Row Barley
}

\author{
N. A. Tinker, D. E. Mather,* B. G. Rossnagel, K. J. Kasha, A. Kleinhofs, P. M. Hayes, D. E. Falk, \\ T. Ferguson, L. P. Shugar, W. G. Legge, R. B. Irvine, T. M. Choo, K. G. Briggs, S. E. Ullrich, \\ J. D. Franckowiak, T. K. Blake, R. J. Graf, S. M. Dofing, M. A. Saghai Maroof, G. J. Scoles, \\ D. Hoffman, L. S. Dahleen, A. Kilian, F. Chen, R. M. Biyashev, D. A. Kudrna, and B. J. Steffenson
}

\begin{abstract}
Quantitative trait locus (QTL) main effects and QTL by environment $(Q T L \times E)$ interactions for seven agronomic traits (grain yield, days to heading, days to maturity, plant height, lodging severity, kernel weight, and test weight) were investigated in a two-row barley (Hordeum vulgare L.) cross, Harrington/TR306. A 127-point base map was constructed from markers (mostly RFLP) scored in 146 random double-haploid (DH) lines from the Harrington/TR306 cross. Field experiments involving the two parents and 145 random DH lines were grown in 1992 and/or 1993 at 17 locations in North America. Analysis of QTL was based on simple and composite interval mapping. Primary QTL were declared at positions where both methods gave evidence for QTL. The number of primary QTL ranged from three to six per trait, collectively explaining 34 to $52 \%$ of the genetic variance. None of these primary QTL showed major effects, but many showed effects that were consistent across environments. The addition of secondary QTL gave models that explained 39 to $80 \%$ of the genetic variance. The QTL were dispersed throughout the barley genome and some were detected in regions where QTL have been found in previous studies. Eight chromosome regions contained pleiotropic loci and/or linked clusters of loci that affected multiple traits. One region on chromosome 7 affected all traits except days to heading. This study was an intensive effort to evaluate QTL in a narrow-base population grown in a large set of environments. The results reveal the types and distributions of QTL effects manipulated by plant breeders and provide opportunities for future testing of marker-assisted selection.
\end{abstract}

M OLECULAR MAPS of plant genomes, used in conjunction with phenotypic measurements, can provide information about chromosome regions that affect quantitative traits. Although knowing whether such regions represent individual quantitative trait loci (QTL) or

N.A. Tinker, and D.E. Mather, Dep. of Plant Science, McGill Univ., 21111 Lakeshore, Ste-Anne-de-Bellevue, QC H9X 3V9, Canada; B.G. Rossnagel, Crop Development Centre, and G.J. Scoles, Dep. of Crop Science and Plant Ecology, Univ. of Sask., Saskatoon, SK S7N 5A8; K.J. Kasha, and D.E. Falk, Crop Science Dep., Univ. of Guelph, Guelph, ON N1G 2W1; A Kleinhofs, A. Kilian, D.A. Kudrna, and S.E. Ullrich, Dep, of Crop and Soil Science, Washington State Univ., Pullman, WA 99164; P.M. Hayes, and F. Chen, Dep. of Crop and Soil Science, Oregon State Univ., Corvallis, OR 97331; T. Ferguson, Alberta Wheat Pool, Calgary AB T2P 2P5; L.P. Shugar, W.G. Thompson \& Sons Ltd., Blenheim, ON NOP 1A0; W.G. Legge, Agric. and Agri-Food Canada, Brandon, MB R7A 5Y3; R.B. Irvine, SIDC, Outlook, SK SOL 2N0; T.M. Choo, Agric. and Agri-Food Canada, Ottawa, ON K1A 0C6; K.G. Briggs, Dep. of Agriculture, Food, and Nutritional Science, Univ. of Alberta, Edmonton, AB T6G 2P5; J.D. Franckowiak, Dep. of Crop and Weed Science, and B.J. Steffenson, Dep. of Plant Pathology, North Dakota State Univ., Fargo, ND 58105; T.K. Blake, Dep. of Plant and Soil Science, Montana State Univ., Bozeman, MT 59715; R.J. Graf, SWP, Saskatoon SK S7N 3R2; S.M. Dofing, Univ. of Alaska, Palmer, AK 99645; M.A. Saghai Maroof, and R.M. Biyashev, Dep. of Crop and Soil Science, VPI and State Univ., Blacksburg VA 24061; D. Hoffman, USDA-ARS, Aberdeen, ID 83210; L.S. Dahleen, USDA-ARS, Fargo, ND 58105. Received 15 Sep. 1995. *Corresponding author (mather@agradm. lan.mcgill.ca).

Published in Crop Sci. 36:1053-1062 (1996). groups of linked QTL is seldom possible, information about QTL regions can help us understand and manipulate genes that affect important plant traits.

The positions of QTL on linkage maps can be estimated by interval mapping. With simple interval mapping (SIM) (Lander and Botstein, 1989; Haley and Knott, 1992), statistical tests are made at many map positions and QTL are inferred to be present where test statistics reach local maxima. Composite interval mapping (Zeng, 1994; Jansen and Stam, 1994) incorporates covariate effects of background markers dispersed throughout the genome. These covariates account for the effects of QTL at positions other than those being tested, increasing the power and precision of QTL mapping.

Evaluation of progeny in multiple environments presents additional challenges and opportunities for QTL analysis. The positions of QTL are presumably constant within a genome, but the effects of QTL alleles can differ among environments because of QTL by environment $(\mathrm{QTL} \times \mathrm{E})$ interaction. Often, QTL analysis is performed separately for each environment, but using data from all environments simultaneously is preferable. Hayes et al. (1993b) used SIM to detect QTL main effects and QTL $\times E$ interactions for progeny tested in multiple environments. Beavis and Keim (in press) suggested mixed models for the analy sis of QTL $\times \mathrm{E}$ interactions, but these methods have not been developed for interval mapping. Tinker and Mather (1995a) described a simplified method of composite interval mapping (sCIM) and extended both SIM and SCIM for the analysis of QTL in multiple environments. They also tested a permutation method to establish significance thresholds. They suggested that SIM be used for making primary QTL inferences, and that sCIM be used to refine those inferences or find additional QTL that may have been masked in the SIM analysis.

Barley (Hordeum vulgare L.), a diploid with a relatively small genome, is well suited to genetic mapping and QTL analysis. Experimental populations of homozygous doubled-haploid $(\mathrm{DH})$ lines can be readily developed. These populations are ideal for QTL analysis, particularly with multiple environments, because each line can be replicated indefinitely. Barley cultivars are normally developed and released as homozygous lines, so inferences about QTL in these populations are useful and meaningful. Results of QTL investigations in barley have been reported by Jensen (1989), Powell et al. (1990a,b), Kjaer et al. (1991), Thomas et al. (1991, 1995), Hackett et al. (1992), Hayes et al. (1993a,b), Barua et al. (1993), Backes et al. (1995), and Laurie et al. (1995).

Abbreviations: cM, centimorgan; QTL, quantitative trait locus or loci; QTL $\times E$, QTL by environment; DH, doubled haploid; SIM, simple interval mapping; sCIM, simplified composite interval mapping; $h^{2}$, heritability. 
Here, we describe an experiment to characterize QTL that affect seven agronomic traits in a DH population from a two-row barley cross. This is the first QTL study in which both parents are North American two-row barley varieties. These parents share a higher degree of coancestry than those used in most other QTL studies. Traits were evaluated in a large and diverse set of environments by collaborators in the North American Barley Genome Mapping Project. The narrow genetic base of this cross, together with the extensive phenotypic evaluation, provides a unique opportunity to investigate the types of QTL typically manipulated by plant breeders.

\section{MATERIALS AND METHODS Plant Material}

'Harrington' (Harvey and Rossnagel, 1984) and 'TR306' are two-row barley selections with spring growth habit. Harrington is an important malting cultivar in North America. TR306, an experimental line developed at the University of Saskatchewan, shares some common ancestry with Harrington but does not have good malting quality. Based on pedigree data, alleles in Harrington and TR306 are expected to be identical by descent at $22 \%$ of loci.

A cross was made between single plants of Harrington and TR306. A population of 150 random $\mathrm{DH}$ lines was produced from the resulting $\mathrm{F}_{1}$ by the Hordeum bulbosum $\mathrm{L}$. method (Kasha and Kao, 1970; Chen and Hayes, 1989). For several of these lines, there were suspected errors in data acquisition, so subsets of DH lines (146 for marker mapping; 145 for QTL analysis) were used in subsequent analyses.

\section{Molecular Markers}

Mapping of more than 200 marker loci (mostly RFLP) was performed in the Harrington/TR306 DH population by Kasha et al. (1995). A subset of 127 markers was chosen to give a base map with relatively uniform coverage. Where possible, the markers in the base map were chosen at 2- to 5-cM intervals. GMendel version 3.0 (Holloway and Knapp, 1994) was used to estimate map order and centimorgan distances for the base map from marker data for $146 \mathrm{DH}$ progeny. Monte Carlo analyses were performed to verify locus ordering. The $\chi^{2}$ statistic was used to test for deviations from the expected $1: 1$ segregation ratio.

\section{Quantitative Traits}

Data for seven agronomic traits (Table 1) were collected in 1992 and/or 1993 at 17 locations, giving a total of 30

Table 1. Agronomic traits measured in the Harrington/TR306 barley cross.

\begin{tabular}{|c|c|c|}
\hline Trait & Units & Method of measurement \\
\hline $\begin{array}{l}\text { Yield } \\
\text { Heading }\end{array}$ & $\mathrm{g} \mathrm{m}^{-2}$ & $\begin{array}{l}\text { Weight of barley grain harvested per unit area. } \\
\text { Number of days from planting until emergence } \\
\text { of } 50 \% \text { of heads on main tillers. }\end{array}$ \\
\hline Maturity & d & $\begin{array}{l}\text { Number of days from planting until physiological } \\
\text { maturity. }\end{array}$ \\
\hline Height & $\mathrm{cm}$ & $\begin{array}{l}\text { Average plant height measured from soil surface } \\
\text { to tip of spike (excluding awns). }\end{array}$ \\
\hline Lodging & $\%$ & $\begin{array}{l}\text { Lodging severity, expressed on a scale of } 0 \text { (no } \\
\text { lodging) to } 100 \text { (complete lodging). }\end{array}$ \\
\hline Kernel weight & mg & $\begin{array}{l}\text { Average weight of an individual barley kernel } \\
\text { (including lemma and palea) from a sample } \\
\text { of } 1000 \text { grains. }\end{array}$ \\
\hline Test weight & $\mathbf{k g ~ h L ^ { - 1 }}$ & $\begin{array}{l}\text { Weight per unit volume of a bulked sample of } \\
\text { barley grain }\end{array}$ \\
\hline
\end{tabular}

Table 2. West to east listing of environments where agronomic traits were measured for the Harrington/TR306 barley cross.

\begin{tabular}{|c|c|c|c|}
\hline Code $\dagger$ & Location & Latitude & Longitude \\
\hline AK93 & Palmer, AK & $61^{\circ} 35^{\prime} \mathrm{N}$ & $149^{\circ} 10^{\prime} \mathrm{W}$ \\
\hline OR92 & lamath Falls, OR & & $121^{\circ} 47^{\prime} \mathrm{W}$ \\
\hline WA92, WA93 & Pullman, WA & $6^{\circ} 46^{\prime} N$ & $117^{\circ} 09^{\prime} \mathrm{W}$ \\
\hline AB93a & Olds, $\mathbf{A B}$ & $1^{\circ} 47^{\prime} \mathrm{N}$ & $114^{\circ} 06^{\prime} \mathrm{W}$ \\
\hline AB92b, AB93b & Irricana, $\mathbf{A B}$ & ${ }^{\circ} 20^{\prime} \mathrm{N}$ & $113^{\circ} 33^{\prime} \mathrm{W}$ \\
\hline $\mathrm{AB} 92 \mathrm{c}, \mathrm{AB} 93 \mathrm{c}$ & Edmonton, $\mathbf{A B}$ & $34^{\prime} \mathrm{N}$ & $113^{\circ} 25^{\prime} \mathrm{W}$ \\
\hline M092, MO93 & Bozeman, MT & $40^{\prime} \mathrm{N}$ & $111^{\circ} 00^{\prime} \mathrm{W}$ \\
\hline SK92a, SK93a & Outlook, SK & ${ }^{\circ} 30^{\prime} \mathrm{N}$ & $107^{\circ} 03^{\prime} \mathrm{W}$ \\
\hline SK92b, SK93b & Saskatoon, SK & $52^{\circ} 10^{\prime} \mathrm{N}$ & $106^{\circ} 40^{\prime} \mathrm{W}$ \\
\hline SK92c, SK93c & Floral, SK & $52^{\circ} 04$ & $106^{\circ} 28^{\prime} \mathrm{W}$ \\
\hline SK92d & Hagen, SK & $52^{\circ} 56^{\prime} \mathrm{N}$ & $105^{\circ} 31^{\prime} \mathrm{W}$ \\
\hline MB92, MB93 & Brandon, MB & $49^{\circ} 50^{\prime} \mathrm{N}$ & $99^{\circ} 57^{\prime} \mathrm{W}$ \\
\hline ND92, ND93 & Langdon, ND & $48^{\circ} 46^{\prime} \mathrm{N}$ & $98^{\circ} 21^{\prime} \mathrm{W}$ \\
\hline ON92a, ON93a & Ailsa Craig, ON & $43^{\circ} 08^{\prime} \mathrm{N}$ & $81^{\circ} 34^{\prime} \mathrm{W}$ \\
\hline ON92b, ON93b & Elora, ON & $43^{\circ} 42^{\prime} \mathrm{N}$ & $80^{\circ} 26^{\prime} \mathrm{W}$ \\
\hline QC92, QC93 & Ste-Anne-de-Bellevue, QC & $45^{\circ} 25^{\prime} \mathrm{N}$ & $73^{\circ} 56^{\prime} \mathrm{W}$ \\
\hline PE92, PE93 & Charlottetown, PE & $46^{\circ} 14^{\prime} \mathrm{N}$ & $63^{\circ} 09^{\prime} \mathrm{W}$ \\
\hline
\end{tabular}

$\dagger$ Environments are coded as follows: uppercase letters identify the Canadian province or U.S. state, numerals identify the year (1992 or 1993), and lowercase suffixes distinguish multiple sites within the same province.

environments (Table 2). Yield was measured in 28 of the 30 environments, heading in 29 , maturity in 15 , height in 27 , lodging in 17, kernel weight in 25 , and test weight in 28 (Table 3). Data for parents and $145 \mathrm{DH}$ lines were acquired from field plots grown using local variety-testing methods and agricultural practices. In 1992, a single randomized complete block was grown at each location, except at MO92, OR92, and WA92 where a random subset of $100 \mathrm{DH}$ lines was tested. In 1993, two randomized complete blocks were grown at each location and replicated observations were made for most traits. Where possible, heritability $\left(h^{2}\right)$ was estimated by analysis of variance as the proportion of phenotypic variance attributable to the DH lines.

\section{QTL Analysis}

Analysis of QTL, performed with the software package MQTL (Tinker and Mather, 1995b), consisted of four steps: (i) performing interval mapping to find evidence of QTL, (ii) estimating thresholds for inferring QTL presence, (iii) inferring the presence of QTL and estimating their positions, and (iv) estimating the additive allelic effects at putative QTL.

\section{Interval Mapping}

Genome-wide QTL searches were performed by SIM and sCIM (Tinker and Mather, 1995a), each with a test for QTL main effects and a test for QTL $\times E$ interaction. Thus, four scans (plots of the test statistic against map position) were produced for each trait. Environments were assumed to have fixed effects.

\section{Estimating Thresholds}

All four scans were based on a test statistic for linear models described by Haley and Knott (1992). Although this test statistic is an approximation of the likelihood ratio, no assumptions were made about its distribution. Instead, significance thresholds were estimated separately for each trait by permutation (Churchill and Doerge, 1994) as follows. Phenotypic values were assigned randomly to DH lines, then SIM was applied to the permuted data to determine the maximum values of the test statistics for QTL main effect and QTL $\times \mathrm{E}$ interaction. This procedure was repeated $\mathbf{5 0 0 0}$ times to approximate the distributions of the maximum test statistics under the null hypothesis (no QTL). These distributions were then used to 
Table 3. Estimated mean $(\hat{\mu})$, phenotypic standard deviation $(\hat{\sigma}), \dagger$ and heritability $\left(h^{2}\right) \ddagger$ for seven agronomic traits in barley measured on parents and double-haploid (DH) lines of Harrington/TR306 in 30 environments.

\begin{tabular}{|c|c|c|c|c|c|c|c|c|c|c|c|c|c|c|c|c|c|c|c|c|c|}
\hline \multirow[b]{2}{*}{ Environment } & \multicolumn{3}{|c|}{$\begin{array}{c}\text { Yield } \\
\mathrm{g} \mathrm{m}^{-2}\end{array}$} & \multicolumn{3}{|c|}{$\begin{array}{c}\text { Heading } \\
\text { d }\end{array}$} & \multicolumn{3}{|c|}{$\begin{array}{c}\text { Maturity } \\
\text { d }\end{array}$} & \multicolumn{3}{|c|}{$\begin{array}{c}\text { Height } \\
\text { cm }\end{array}$} & \multicolumn{3}{|c|}{$\begin{array}{l}\text { Lodging } \\
\%\end{array}$} & \multicolumn{3}{|c|}{$\begin{array}{c}\text { Kernel weight } \\
\text { mg }\end{array}$} & \multicolumn{3}{|c|}{$\begin{array}{c}\text { Test weight } \\
\text { kg hL }\end{array}$} \\
\hline & $\hat{\boldsymbol{\mu}}$ & $\hat{\boldsymbol{\sigma}}$ & $h^{2}$ & $\hat{\mathbf{\mu}}$ & $\hat{\boldsymbol{\sigma}}$ & $h^{2}$ & $\hat{\boldsymbol{\mu}}$ & $\hat{\boldsymbol{\sigma}}$ & $h^{2}$ & $\hat{\boldsymbol{\mu}}$ & $\hat{\boldsymbol{\sigma}}$ & $h^{2}$ & $\hat{\mathbf{\mu}}$ & $\hat{\boldsymbol{\sigma}}$ & $h^{2}$ & $\hat{\mathbf{\mu}}$ & $\hat{\boldsymbol{\sigma}}$ & $h^{2}$ & $\hat{\boldsymbol{\mu}}$ & $\hat{\boldsymbol{\sigma}}$ & $h^{2}$ \\
\hline AK93 & 507 & 155 & 0 & 55 & 1.8 & 29 & 83 & 2.3 & 0 & 72 & 8.9 & 9 & & & & 47 & 3.0 & 49 & 67 & 1.3 & 37 \\
\hline OR92 & 742 & 114 & & 95 & 2.1 & & & & & 104 & 6.9 & & 5 & 10 & & & & & 74 & 1.8 & \\
\hline WA92 & 330 & 67 & & 77 & 1.2 & & & & & 66 & 5.4 & & & & & 42 & 2.2 & & 64 & 1.4 & \\
\hline WA93 & 710 & 74 & 12 & 57 & 1.1 & & & & & 93 & 6.3 & 26 & & & & 49 & 3.1 & 75 & 69 & 1.3 & 47 \\
\hline AB93a & 507 & 47 & 31 & & & & 117 & 2.0 & 12 & & & & 48 & 22 & & 41 & 3.4 & & 62 & 2.2 & \\
\hline AB92b & 407 & 35 & & 65 & 1.3 & & 98 & 3.7 & & 99 & 6.1 & & & & & 45 & 3.4 & & 59 & 1.8 & \\
\hline AB93b & 436 & 55 & 18 & 62 & 1.0 & & 103 & 1.2 & & 87 & 7.6 & & & & & 52 & 2.7 & & 66 & 1.9 & \\
\hline $\mathrm{AB} 92 \mathrm{c}$ & 495 & 49 & & 61 & 1.7 & & 92 & 1.3 & & 90 & 5.8 & & & & & 48 & 3.0 & & 71 & 1.2 & \\
\hline $\mathrm{AB} 93 \mathrm{c}$ & & & & 54 & 1.5 & 51 & & & & & & & & & & & & & & & \\
\hline MO92 & 732 & 103 & & 62 & 1.7 & & & & & 92 & 4.5 & & 28 & 19 & & & & & 68 & 1.8 & \\
\hline MO93 & 677 & 110 & 11 & 70 & 1.9 & 67 & & & & 118 & 3.5 & 29 & & & & & & & 66 & 2.2 & \\
\hline SK92a & 631 & 111 & & 63 & 2.2 & & 102 & 2.2 & & 117 & 5.2 & & 60 & 24 & & 46 & 3.7 & & 57 & 3.3 & \\
\hline SK93a & 499 & 59 & 19 & 57 & 1.7 & 54 & 91 & 1.9 & 27 & 95 & 4.0 & 39 & 42 & 29 & 23 & 37 & 4.1 & 68 & 61 & 2.9 & 55 \\
\hline SK92b & 468 & 29 & & 51 & 1.4 & & & & & 79 & 4.6 & & & & & 42 & 3.1 & & 64 & 1.4 & \\
\hline SK93b & 436 & 58 & 17 & 60 & 1.7 & 63 & & & & & & & & & & 37 & 3.3 & 51 & 65 & 2.6 & 36 \\
\hline SK92c & 454 & 44 & & 64 & 1.8 & & & & & 67 & 8.0 & & & & & 46 & 3.2 & & 65 & 1.5 & \\
\hline SK93c & 450 & 38 & 19 & 60 & 2.2 & 70 & & & & 79 & 4.5 & 35 & & & & 46 & 2.4 & 74 & 68 & 1.1 & 65 \\
\hline SK92d & 322 & 68 & & 57 & 1.1 & & & & & 60 & 9.3 & & 2 & 5 & & 49 & 2.9 & & 68 & 1.4 & \\
\hline MB92 & 604 & 52 & & 59 & 1.4 & & 95 & 1.8 & & 100 & 4.4 & & 75 & 10 & & 42 & 3.6 & & 64 & 1.9 & \\
\hline MB93 & 471 & 71 & 58 & 63 & 2.3 & 46 & 93 & 2.0 & 40 & 91 & 4.2 & 54 & 75 & 15 & 31 & 38 & 3.8 & 79 & 61 & 2.7 & 77 \\
\hline ND92 & 523 & 59 & & 69 & 1.3 & & & & & 102 & 5.7 & & & & & 44 & 3.6 & & 66 & 1.9 & \\
\hline ND93 & & & & 64 & 1.5 & 39 & & & & 96 & 5.6 & 18 & 92 & 10 & 9 & & & & & & \\
\hline ON92a & 288 & 37 & & 53 & 1.2 & & 84 & 1.1 & & 84 & 6.0 & & 2 & 5 & & 36 & 4.0 & & 53 & 3.0 & \\
\hline ON93a & 291 & 52 & 26 & 55 & 1.4 & 36 & 77 & 0.7 & 22 & 84 & 5.9 & 32 & 10 & 16 & 3 & 38 & 3.7 & & 57 & 2.2 & \\
\hline ON92b & 273 & 48 & & 59 & 1.3 & & 98 & 0.7 & & 94 & 4.8 & & 44 & 26 & & 33 & 3.1 & & 56 & 2.5 & \\
\hline ON93b & 321 & 40 & 56 & 59 & 0.6 & 44 & 93 & 0.5 & & 94 & 4.1 & 39 & 3 & 9 & 32 & 32 & 4.0 & & 57 & 2.8 & \\
\hline QC92 & 562 & 51 & & 53 & 2.4 & & 93 & 1.2 & & 83 & 5.3 & & 27 & 23 & & 53 & 2.7 & & 66 & 2.0 & \\
\hline QC93 & 421 & 39 & 42 & 52 & 1.6 & 75 & 85 & 1.9 & 37 & 68 & 5.5 & 23 & 22 & 23 & 26 & 42 & 3.0 & 72 & 66 & 1.6 & 58 \\
\hline PE92 & 396 & 66 & & 57 & 0.9 & & & & & 104 & 4.8 & & 83 & 21 & & 41 & 5.0 & & 56 & 3.1 & \\
\hline PE93 & 494 & 54 & 66 & 61 & 0.9 & 50 & & & & 88 & 5.9 & 29 & 51 & 22 & 52 & 39 & 4.4 & 82 & 62 & 2.9 & 76 \\
\hline Average & 467 & 59 & 35 & 61 & 1.5 & 54 & 91 & 1.4 & 32 & 90 & 5.3 & 33 & 41 & 17 & 25 & 41 & 3.5 & 71 & 63 & 2.2 & 61 \\
\hline
\end{tabular}

† Phenotypic standard deviation after fitting a block effect in environments with two replications.

$\ddagger$ Estimated as the percentage of phenotypic variance attributable to DH lines in environments with two replications.

estimate thresholds to maintain the genome-wise type-I error rate below 5\%. In simulation studies, Tinker and Mather (1995a) found this procedure provided good control of type-I error rate for SIM, even when environments had different amounts of residual variance. Thresholds for sCIM were not estimated, for reasons given by Tinker and Mather (1995a).

\section{Making Inferences and Estimating QTL Positions}

Two levels of QTL inference were made. Primary QTL were declared at positions where SIM peaks were significant for either QTL main effects or QTL $\times E$ interaction and where sCIM peaks were also strong. Secondary QTL were declared where either SIM or sCIM, but not both, gave evidence for a QTL. Estimates of the positions of primary and secondary QTL corresponded to the peaks of the sCIM scans. When evidence for a QTL main effect and a QTL $\times E$ interaction were found near the same position, a single QTL was inferred based on the effect that seemed strongest.

\section{Estimating Allelic Effects}

Main effects and QTL $\times E$ interactions were estimated in multi-locus linear models. Each estimated main effect corresponded to the average difference between homozygous classes for a given QTL. Estimates were made for a model that included only primary QTL, as well as for a model that included both primary and secondary QTL. Reduction in variance $\left(R^{2}\right)$, relative to a model that included only the environmental main effects, was estimated for models with four levels of complexity: Model 1, primary QTL main effects, Model 2, primary QTL main effects and primary QTL $\times E$ interactions, Model 3, main effects and QTL $\times E$ interactions for both primary and secondary QTL, and Model 4, effects for all background markers estimated separately by environment. The model with all background markers did not contain terms for specific QTL.

\section{RESULTS \\ Molecular Markers}

The 127-marker base map (Fig. 1) contained a total linkage distance of $1270 \mathrm{cM}$, with an average distance between markers of $10.5 \mathrm{cM}$. There were gaps greater than $25 \mathrm{cM}$ on chromosomes 2, 5, and 7. In 500 Monte Carlo analyses, the estimated order of markers in the base map remained constant. Two loci (MWG844 on chromosome 2 and ABG715 on chromosome 4) showed segregation ratios that differed significantly from $1: 1(P<0.01)$ by the $\chi^{2}$ test. Slight differences in estimated distances between markers from the previously published map (Kasha et al., 1995) were caused by the inclusion of additional marker information, the exclusion of four progeny, the exclusion of markers from tightly linked clusters, and the exclusion of markers with large amounts of missing data. The data set for the markers contained in the base map was $95 \%$ complete.

\section{Quantitative Traits}

There were large differences, among environments, in mean performance for all traits (Table 3). Many of the environments with the highest phenotypic standard deviations also had the lowest $h^{2}$, suggesting that there 


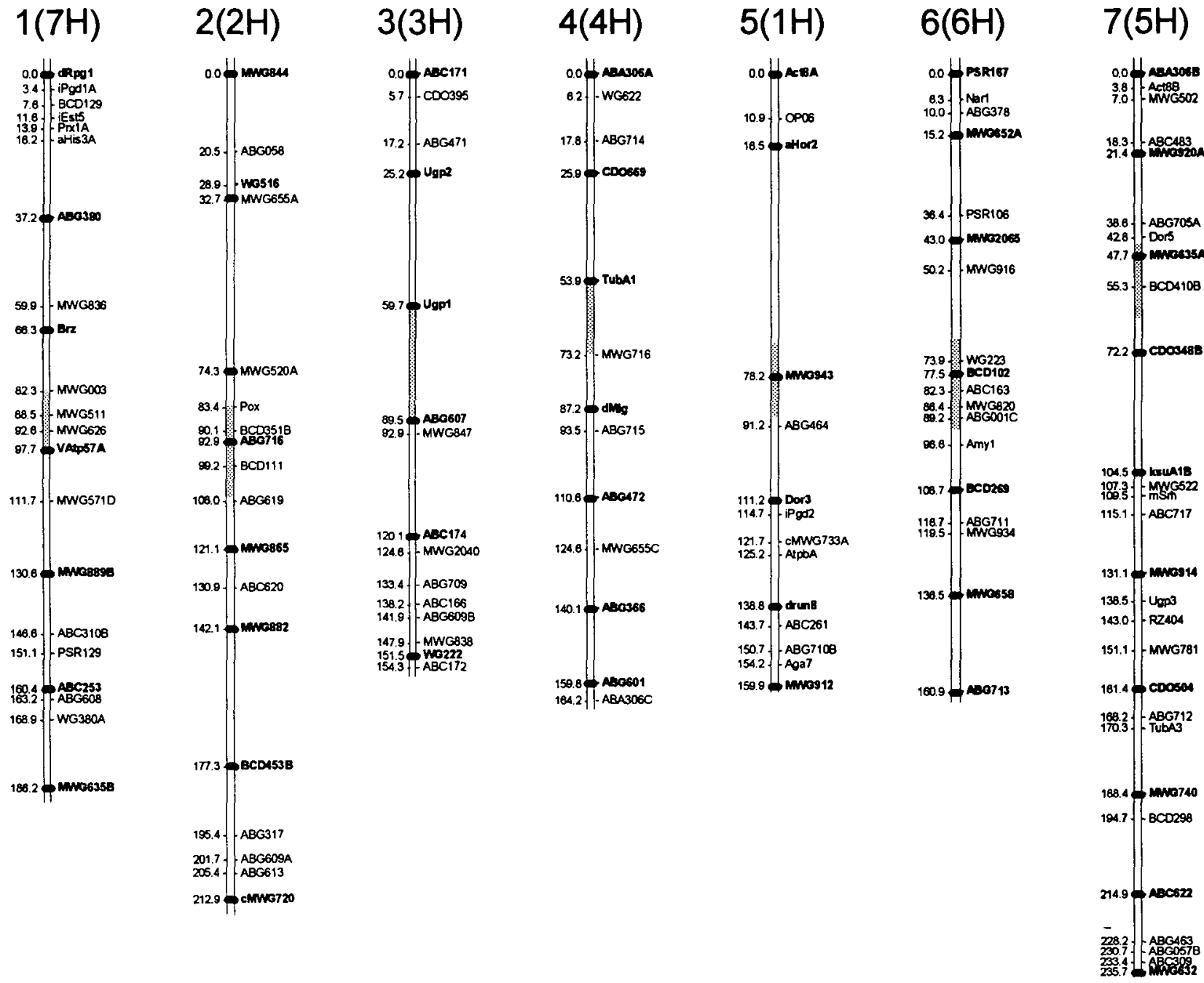

Fig. 1. Linkage map from the Harrington/TR306 barley cross showing approximate cM positions (Kosambi function) of 127 markers (mostly RFLP) on seven barley chromosomes. Chromosome designations in parentheses (2H, 7H, etc.) are those proposed by Shepherd and Islam (1992). Plus arms are shown at the top of the figure and approximate centromere positions are shaded. Loci marked with a heavy band are those used as background markers in composite interval mapping.

was considerable heteroscedasticity (differences in the amount of non-genetic variance) among environments.

Averaged across environments, quantitative trait distributions were approximately normal, with ranges of about four to six standard deviations (Table 4). For each trait, the mid-parent value was approximately equal to the mean of the DH lines. For yield, heading, and maturity, the values of the parents differed by less than one standard deviation, and there were transgressive $\mathrm{DH}$ segregates that differed from both parents by approximately two standard deviations or more. For the remaining four traits, the parents differed by more than one standard deviation. TR306 had taller plants, higher kernel weight, higher test weight, and less lodging than Harrington. For these four traits, there were transgressive DH segregates that differed from both parents by more than one standard deviation.

Neither lodging nor yield were correlated $(P=0.05)$

Table 4. Quantitative trait distributions based on means of doubled-haploid lines from the Harrington/TR306 barley cross.

\begin{tabular}{|c|c|c|c|c|c|c|}
\hline \multirow[b]{2}{*}{ Trait } & \multicolumn{4}{|c|}{ Doubled-haploid lines } & \multicolumn{2}{|c|}{ Mean of parents } \\
\hline & $\hat{\boldsymbol{\mu}} \dagger$ & $\hat{\sigma} \ddagger$ & Minimum $\ddagger$ & Maximum $\ddagger$ & Harrington $\ddagger$ & TR306ł \\
\hline $\begin{array}{l}\text { Yield }\left(\mathrm{g} \mathrm{m}^{-2}\right) \\
\text { Heading (days) } \\
\text { Maturity (days) } \\
\text { Height (cm) } \\
\text { Lodging }(\%) \\
\text { Kernel weight }(\mathrm{mg}) \\
\text { Test weight (kg hL-1) }\end{array}$ & $\begin{array}{r}476 \\
58 \\
93 \\
89 \\
41 \\
42 \\
64\end{array}$ & $\begin{array}{r}21.2 \\
1.0 \\
0.8 \\
2.8 \\
6.8 \\
2.3 \\
1.1\end{array}$ & $\begin{array}{r}-60.1 \\
-1.9 \\
-1.8 \\
-7.6 \\
-15.7 \\
-6.2 \\
-3.4\end{array}$ & $\begin{array}{r}52.5 \\
2.2 \\
1.8 \\
5.9 \\
18.0 \\
18.0 \\
6.1 \\
2.4\end{array}$ & $\begin{array}{r}2.5 \\
-0.1 \\
0.2 \\
-3.0 \\
4.2 \\
-3.3 \\
-1.5\end{array}$ & $\begin{array}{r}7.9 \\
-0.3 \\
0.2 \\
2.1 \\
-2.8 \\
3.0 \\
1.2\end{array}$ \\
\hline
\end{tabular}

$\dagger$ Unadjusted mean of all observations in all environments.

‡ Expressed as deviations from $\hat{\mu}$. Observations within each environment were standardized to a mean of zero prior to computing the line means. 
Table 5. Pearson phenotypic correlation coefficients among seven agronomic traits in barley based on means of doubled-haploid lines.

\begin{tabular}{lrccccc}
\hline & Yield & Heading & Maturity & Height & Lodging & $\begin{array}{c}\text { Kernel } \\
\text { weight }\end{array}$ \\
\hline Heading & -0.19 & & & & & \\
Maturity & 0.24 & 0.50 & & & & \\
Height & ns & ns & 0.35 & & & \\
Lodging & -0.42 & ns & -0.34 & ns & & \\
Kernel weight & 0.50 & ns & 0.29 & 0.40 & -0.30 & \\
Test weight & 0.46 & ns & 0.17 & 0.21 & -0.36 & 0.47 \\
\hline
\end{tabular}

ns $=$ Not significantly different from zero $(P=0.05)$.

with height (Table 5). Heading was not correlated with any trait except yield and maturity. The correlation between yield and heading was negative. All significant correlations that involved lodging were also negative. The strongest negative correlation was between yield and lodging. All remaining correlations were positive. The strongest positive correlations were between heading and maturity, and among kernel weight, test weight, and yield.

\section{QTL Analysis}

A total of 56 putative QTL were found (Fig. 2). Of these, 31 were primary QTL and 25 were secondary QTL. There were three to six primary QTL per trait, most with strong main effects. Allelic effects of primary QTL were relatively constant across environments (bar charts in Fig. 2) and most primary QTL $\times E$ interactions resulted from changes in magnitude rather than sign of allelic effect. Primary QTL with strong crossover-type interactions included a QTL for yield on chromosome 1 , a QTL for maturity on chromosome 6, a QTL for lodging on chromosome 4, QTL for kernel weight on chromosomes 4 and 7, and a QTL for test weight on chromosome 1 . These regions had peaks that were much stronger in the scans for QTL $\times \mathrm{E}$ than in the scans for QTL main effect.

Most primary QTL were within one of eight genomic regions that affected more than one trait. One region near the end of the plus arm of chromosome 7 affected all traits except heading. In this region, the presence of a Harrington allele increased lodging and decreased yield, maturity, height, kernel weight, and test weight. For secondary QTL, main effects tended to be smaller than those of the primary QTL, and many of the secondary QTL were detected because of their QTL $\times E$ interactions. Some notable exceptions included secondary QTL for heading (on chromosomes 3 and 6), and yield (on chromosomes $1,2,5$, and 6), for which strong main effects were found.

The QTL that accounted for the greatest proportions of phenotypic variance were those that affected heading and kernel weight (Table 6). For yield and lodging, relatively little phenotypic variance was accounted for by main effects of primary QTL. With the addition of secondary QTL and QTL $\times E$ interactions, the proportion of phenotypic variance explained for yield was approximately the same as that for maturity, height, or test weight. The proportions of genetic variance explained by primary QTL were smallest for yield (34\%) and largest for heading (52\%). Full QTL models (i.e., with primary and secondary main effects and QTL $\times \mathrm{E}$ interactions) explained $39 \%$ (for test weight) to $80 \%$ (for heading) of the genetic variance. Models that contained all of the background markers (with no specific QTL effects) explained more variance than the full QTL models. The proportions of variance explained by the background markers were approximately equal to or greater than $h^{2}$ (Table 6).

\section{DISCUSSION Quantitative Traits}

\section{Estimates of Heritability}

We chose to perform unreplicated tests in 1992 to maximize the number of $\mathrm{DH}$ lines and environments. This approach was justified by theoretical work of Knapp and Bridges (1990), although estimating $h^{2}$ within the non-replicated environments was not possible. The estimated $h^{2}$ values varied among 1993 environments; in some environments, no genetic variance was detected. Presumably, large differences in $h^{2}$ were also present among the 1992 environments and among the nonreplicated 1993 environments.

\section{Correlation among Traits}

Genetic correlation among traits is caused by linked or pleiotropic QTL. The correlation coefficients observed among these agronomic traits suggested that chromosome segments associated with reduced lodging were associated with increased values of most other traits. The lack of correlation between heading and most other traits suggested that loci affecting heading were independent of those affecting other traits. Correlations among yield, heading, and maturity suggested that yield was increased by factors that allowed longer periods of grain fill. Although correlations were based on means of lines across many environments, they still included a fraction of non-genetic correlation.

\section{Analysis of QTL}

\section{Error Control with Permuted Thresholds}

Based on permutation-derived thresholds, the expected rate of type-I error for primary QTL was less than 5\% per SIM scan. The rate may have actually been lower because primary QTL were not declared at positions where there was no sCIM peak. However, type-I error was controlled separately for main effects and interactions, and separately for each trait. Therefore, the type-I error rate across this entire study was probably greater than $5 \%$.

\section{Primary versus Secondary QTL}

Because of the use of permutation-derived thresholds for SIM, the primary QTL are those in which we have most confidence. Primary QTL also showed the most consistent and largest effects. Because we were unable 

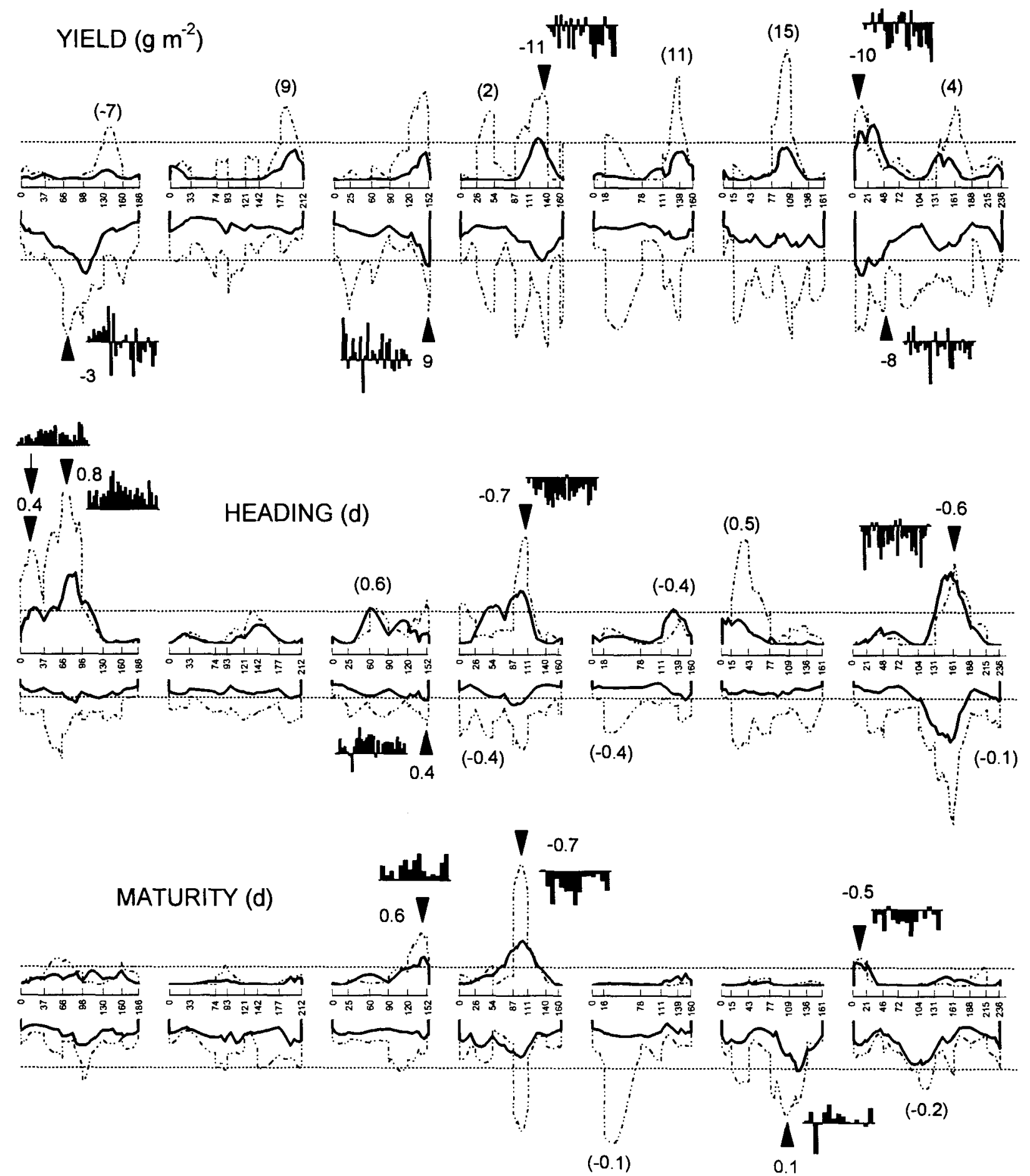

Fig. 2. Scans of a test statistic for simple interval mapping (SIM, solid lines) and simplified composite interval mapping (sCIM, broken lines) for QTL main effects (above axes) and QTL by environment interactions (below axes). Scans are shown for seven traits as indicated. Barley chromosomes 1 to 7 are shown left to right, oriented with the plus arm on the left. Horizontal scales show approximate cM positions of background markers (see Fig. 1). Horizontal dashed lines show thresholds for testing SIM. These thresholds were estimated from 5000 permutations of the data to maintain experiment-wide type I error rate below 5\%. Positions of primary QTL are shown by darkened triangles located at the peaks of the SCIM scans. Estimated QTL main effects (i.e., the average effect of substituting two Harrington alleles for two TR306 alleles) are shown for primary QTL (numbers beside the darkened triangles) and for secondary QTL (in parentheses). Bar charts beside each primary QTL depict the relative magnitudes of estimated QTL effects for each environment (arranged west to east).

to derive a threshold for use with SCIM, there was some uncertainty associated with this method. Therefore, inferences drawn solely from SCIM were classified as secondary QTL. Nevertheless, sCIM contributed further information useful for interpreting QTL inferences.
In some cases, sCIM gave strong evidence for a QTL at a position where the SIM scan was not significant. This result can occur for a number of reasons. First, sCIM can detect QTL with smaller effects because it accounts for the genetic component of the background 

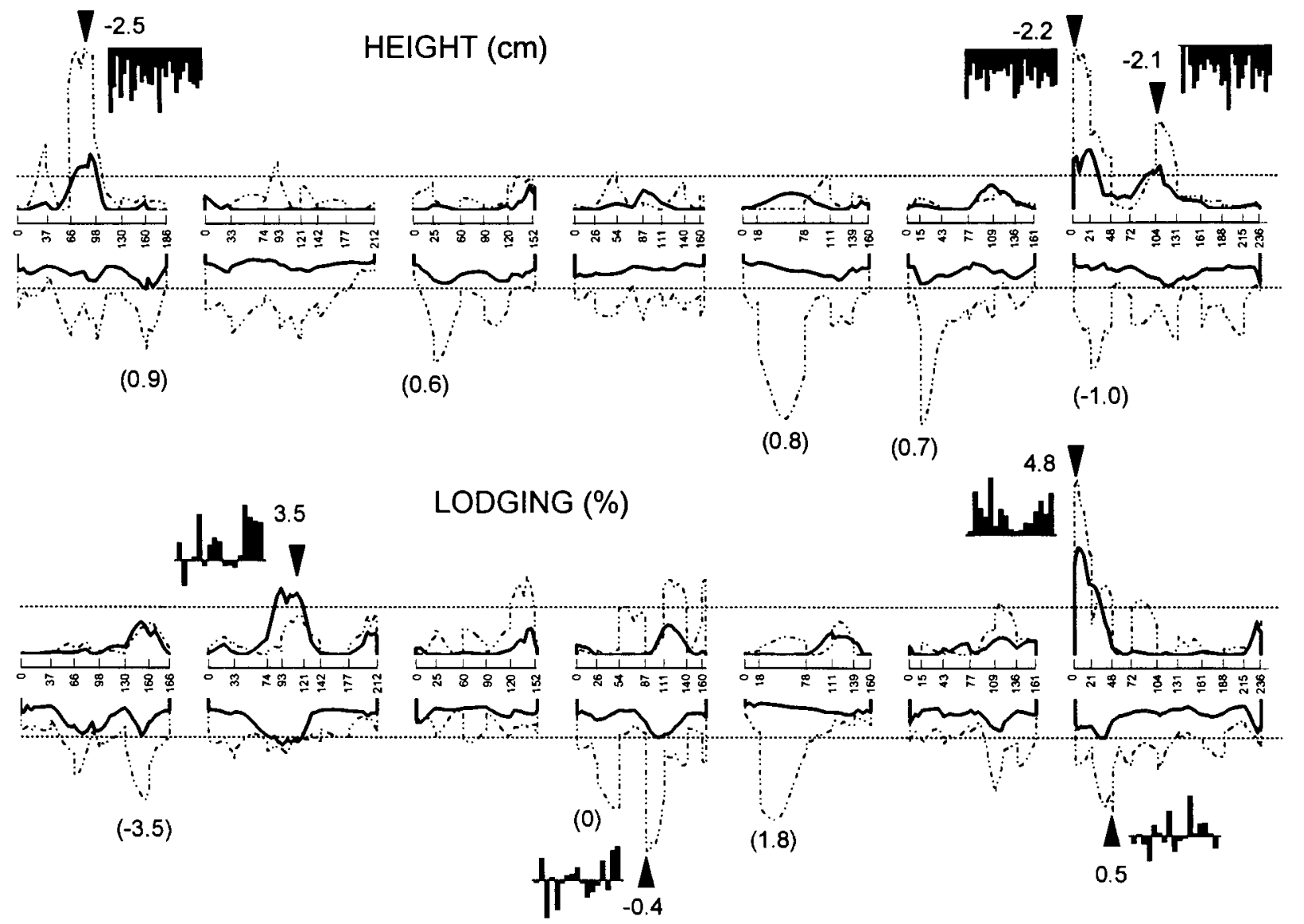

(0.8)

$(0.7)$
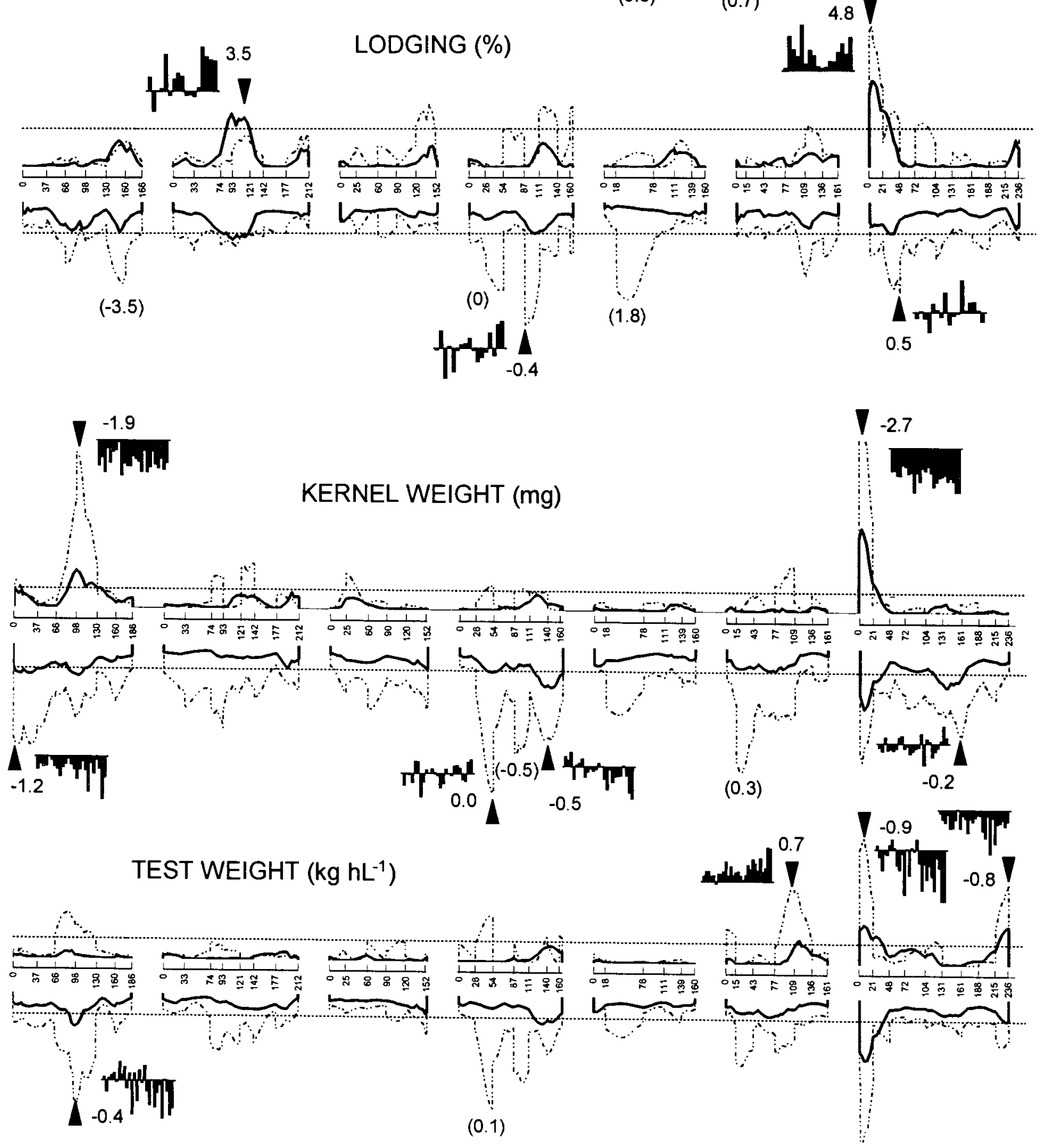

Fig. 2 continued. 
Table 6. Average percentages of within-environment phenotypic and genetic (in parentheses) $\dagger$ variance, for different models, explained by QTL for seven agronomic traits in barley.

\begin{tabular}{lrccc}
\hline & \multicolumn{4}{c}{ Model $~$} \\
\cline { 2 - 5 } Trait & \multicolumn{1}{c}{1} & 2 & 3 & 4 \\
\hline Yield & $3(9)$ & $12(34)$ & $21(60)$ & $47(100)$ \\
Heading & $20(37)$ & $28(52)$ & $43(80)$ & $65(100)$ \\
Maturity & $8(25)$ & $14(44)$ & $18(56)$ & $47(100)$ \\
Height & $11(33)$ & $14(42)$ & $21(64)$ & $51(100)$ \\
Lodging & $4(16)$ & $10(40)$ & $14(56)$ & $46(100)$ \\
Kernel weight & $27(38)$ & $36(51)$ & $38(53)$ & $65(92)$ \\
Test weight & $11(18)$ & $23(38)$ & $24(39)$ & $59(97)$ \\
\hline
\end{tabular}

† Estimated based on the average $h^{2}$ from Table 3 (estimates greater than $100 \%$ have been truncated).

¥ Model 1, main effects for primary QTL; Model 2, main effects and QTL by environment interactions for primary QTL; Model 3, main effects and QTL by environment interactions for primary and secondary QTL; Model 4, main effects and interactions with environment for all background markers.

variance; for yield, many strong sCIM peaks for main effect were located in regions where SIM peaks were present but not significant (Fig. 2). Second, sCIM shows regions where there is evidence for multiple linked QTL. In many cases (e.g., lodging and kernel weight on chromosome 4, Fig. 2) sCIM suggested the presence of linked QTL that interacted with environment.

There were also instances where SIM gave evidence for a QTL but sCIM did not. Such a result could arise because SCIM has eliminated sampling variance that contributed to type-I error for SIM. Alternatively, it could indicate that the SIM scan was influenced by two separate QTL that were not strong enough to manifest themselves as two separate peaks in the sCIM scan. This situation only occurred at positions where SIM was marginally significant, so we considered these peaks as evidence of secondary QTL.

\section{Estimates of Allelic Effect}

The assumption of fixed environments restricted the estimates of allelic effect to the specific environments used, but it allowed for SIM and SCIM to be implemented with simple methods of least-squares regression. Furthermore, it allowed us to consider the possibility of observable patterns (e.g., east-west or north-south trends) of QTL $\times E$ interaction. Several QTL $\times E$ interactions were clearly crossover interactions, with positive effects in some environments, negative effects in other environments, and with no significant main effects. Some QTL $\times \mathrm{E}$ interactions were clearly due to changes in magnitude, while other QTL $\times \mathrm{E}$ interactions could not be easily classified. There was substantial sampling error associated with single-environment estimates, so random fluctuations in the estimated direction of small QTL effects were expected.

\section{Interpretation of QTL}

The data presented here fit the classical concept that traits exhibit quantitative variation when they are affected by multiple loci with small effects. All traits examined in this study were affected by at least three primary QTL. Often, the largest three or four QTL for a given trait had effects that were approximately equal, and none of the QTL exhibited a single overwhelming effect. Secondary QTL had effects that were less consistent across environments. Presumably there were other undetected QTL with small effects that would be difficult to detect in any experiment.

For yield, heading, and maturity, both parents contributed approximately the same number of favorable alleles. Thus, even though these traits were similar in the parents, many progeny had values that were substantially higher or lower than the midparent values. For the remaining traits, the predominant directions of primary QTL effects are reflected in the differences between the parents. The fact that these traits still showed some transgressive segregation may be accounted for by secondary QTL and other QTL that were not detected in this experiment.

None of the QTL models explained all of the estimated genetic variance for a trait (Table 6). This suggests the presence of undetected QTL, the presence of epistasis, or both. Major epistatic interactions did not seem to be present for these traits because phenotypic distributions were approximately normal and centered on mid-parent values (Table 4). Furthermore, models containing all background markers explained all or most of the genetic variance (Table 6), even though they contained no interlocus interactions. Although minor QTL $\times E$ interactions may have been present, we conclude that additive QTL effects were responsible for most of the genetic variance for these agronomic traits.

This experiment could not determine whether chromosome regions that affected multiple traits contained a single pleiotropic locus, or whether they contained two or more linked loci. Either situation would have contributed toward genetic correlations among traits. In regions with multiple QTL, the signs (positive or negative) of allelic effect were usually in agreement with the observed correlations among traits. Most notably, the allelic effects near $\mathrm{cM}$ position 0 on chromosome 7 seemed to be reflected in the correlations among traits. Not all QTL followed this pattern. For example, two regions (one on chromosome 3, and one on chromosome 4) contained primary QTL that affected both yield and heading in the same direction. Thus, the small negative correlation between yield and heading must have been due to other minor QTL effects, or to environmental correlation.

\section{Interpretation of $\mathbf{Q T L} \times \mathbf{E}$}

By including many environments in this study, we have identified QTL that were relevant in a broad spectrum of environments. Furthermore, by performing QTL analyses that were combined over environments, we should have gained precision for estimating QTL position. The genomic position of a QTL is constant but the effect of a QTL may vary by environment. The QTL analyses presented here accounted for QTL $\times E$ interaction, and provided a formal test for its presence. While most of the primary QTL showed relatively constant effects, there was clearly a considerable amount of QTL $\times E$. Even QTL detected at positions where QTL $\times E$ was not significant seemed to have effects that varied by environment 
(Fig. 2). In reality, we expect that some $\mathrm{QTL} \times \mathrm{E}$ is always present.

By treating environments as fixed, we were abled to estimate the effects of QTL in specific environments. The summary of effects presented here (Fig. 2) illustrates some general trends. For example, some of the QTL for yield showed allelic effects that changed sign depending on environment. There also seemed to be a trend toward stronger expression of QTL for kernel weight or test weight in eastern environments. A detailed examination of specific environments is beyond the scope of this report.

\section{Comparison to Other Barley QTL}

The Steptoe/Morex barley map (Kleinhofs et al. 1993) shared many common markers with the map reported here, so the QTL studied by Hayes et al., (1993b) provided the best opportunity for comparing the positions of QTL. Of the five primary QTL for yield, only the QTL $\times$ E interaction on chromosome 1 seemed to correspond to a yield QTL in Steptoe/Morex. For heading, the two primary QTL on chromosome 1 may have corresponded to QTL detected in Steptoe/Morex. Two of the three primary QTL for plant height (that on chromosome 1 , and that closest to the centromere of chromosome 7) corresponded closely with height QTL detected in Steptoe/Morex. Of the four primary lodging QTL, those on chromosomes 2 and 4 may have corresponded with QTL detected in Steptoe/Morex. For most traits, there were also a few secondary QTL that were coincident with QTL detected in Steptoe/Morex.

None of the QTL detected by Kjaer et al. (1991) or by Hackett et al. (1992) seem to be near regions where we have located QTL in Harrington/TR306. Traits studied by Barua et al. (1993) and Thomas et al. (1995) in a two-row cross were affected strongly by the denso locus on chromosome 3 . The denso locus was not polymorphic in Harrington/TR306, and there were no QTL in the region where we would expect denso to be located. Locus $V$ on chromosome 2 conditions the two-row vs six-row character in barley, but it may also affect many quantitative traits (e.g., Powell et al., 1990b). This locus was not polymorphic in Harrington/TR306 and, apart from a QTL with a small effect on lodging, we found no QTL this region.

Powell et al. (1990a) found a QTL near Amy1 with significant effects on kernel weight and single plant yield. We also detected QTL for test weight and yield in Harrington/TR306 in the region of Amyl. In other reports, kernel weight has been associated with the GPert locus (Thomas et al., 1991) or a QTL named $K w 1$ (Jensen, 1989). Both of these loci are on chromosome 7, but we cannot determine their location on the Harrington/TR306 map. Of the primary QTL we found in Harrington/ TR306, it seems that any of the following QTL could have coincided with QTL detected by Backes et al. (1995) in a two-row winter barley population: the yield QTL on chromosomes 4 and 7, the heading QTL on chromosome 7, two height QTL on chromosome 7, lodging QTL on chromosomes 4 and 7, and the kernel weight QTL on chromosomes 4 and 7 .
Genes affecting heading were studied by Laurie et al. (1995) in a spring $\times$ winter barley cross. None of the five major genes that affected vernalization or photoperiod response in that cross corresponded with positions of heading QTL in Harrington/TR306. However, several of the primary QTL in Harrington/TR306 (on chromosomes 1, 3, and 4) were detected in the vicinity of three QTL reported by Laurie et al. (1995) for earliness-per-se (i.e., they affect developmental rate without being dependent on environmental cues). This suggests that variation in heading date in Harrington/TR306 was caused by polymorphism at earliness-per-se genes - a speculation that is consistent with the absence of major QTL $\times E$ interactions for this trait.

We expect to find different QTL in different populations because different alleles segregate, but there are other reasons why different experiments may not detect the same QTL. Identical experiments that use different samples from the same population can detect different subsets of QTL. Experiments may use different molecular markers and different maps that cover different regions of the genome. Experiments may be conducted in dissimilar environments and/or with different methods for measuring traits, so QTL $\times E$ interaction can contribute to the discovery of different QTL. Different methods of QTL analysis may emphasize control of different types of statistical error. For example, we would have detected many additional QTL in this study had we controlled comparison-wise rather than genome-wise type-I error rate. Despite these uncertainties, comparisons among QTL studies can reveal chromosome regions where QTL frequently segregate. This may provide guidance for the eventual identification of specific genes that are responsible for quantitative trait variation.

Robertson (1985) postulated that many QTL may represent the same genes for which qualitative mutations are known. In barley, many morphological mutations have been described, but their map positions are known only approximately. Integration of morphological markers into current genetic maps will provide opportunities to find relationships between quantitative and qualitative loci.

\section{CONCLUSIONS}

We detected a total of 56 QTL for seven agronomic traits in the two-row barley cross Harrington/TR306. Agronomic data were collected in a large and diverse set of environments, allowing for the detection of QTL that were expressed consistently across environments as well as those that interacted with environment. The numbers of QTL, their positions, and their allelic effects were consistent with the quantitative trait distributions and the correlations among traits. Some QTL were at positions similar to those of QTL detected in other barley populations.

Most QTL have been studied in populations derived from relatively wide crosses. In terms of genetic diversity for agronomic traits, the Harrington/TR306 population is more typical of breeding populations. Breeders often make crosses between related lines that show small differences for several traits. Harrington and TR306, 
with $22 \%$ common ancestry, were almost identical in mean performance for three traits, and slightly different in mean performance for four other traits. Therefore, the number of QTL and the magnitude of QTL effects revealed by this study are probably typical of what is manipulated in plant breeding programs. At first glance, the identification of new lines that combine all positive attributes might seem trivial. However, a population from this cross will contain segregating QTL in approximately 13 regions. Ignoring linkage, the frequency of a "perfect genotype" in this DH population is less than one in 8000 .

Many of the QTL detected in this study had effects that were highly consistent across many environments. These QTL may be amenable to marker-assisted selection. Regardless of whether or not QTL are used for marker-assisted selection, information about QTL contributes to a greater understanding of the genetic control of important traits and provides important insight to plant breeders.

\section{ACKNOWLEDGMENTS}

In Canada, this research was supported by grants from the Natural Sciences and Engineering Research Council of Canada, Agriculture Canada and the Brewing and Malting Barley Research Institute. In the USA, this research was supported by the North American Barley Genome Mapping Project, with funds from USDA-CSRS, barley growers, and the malting and brewing industry. We thank our technical staff for their patience and skill in collecting approximately 58,000 observations used in this report.

\section{REFERENCES}

Backes, G., A. Graner, B. Foroughi-Wehr, G. Fischbeck, G. Wenzel, and A. Jahoor. 1995. Localization of quantitative trait loci (QTL) for agronomic important characters by use of a RFLP map in barley (Hordeum vulgare L.). Theor. Appl. Genet. 90:294-302.

Barua, U.M., K.J. Chalmers, W.T.B. Thomas, C.A. Hackett, V. Lea, P. Jack, B.P. Forster, R. Waugh, and W. Powell. 1993 Molecular mapping of genes determining height, time to heading, and growth habit in barley (Hordeum vulgare). Genome 36:10801087.

Beavis, W.D., and P. Keim. 1995. Identification of QTL that are affected by environment. p. 123-149. In M.S. Kang and H.G Gauch, Jr. (ed.) Genotype-by-environment interaction. CRC Press, Boca Raton, FL.

Chen, F., and P.M. Hayes. 1989. A comparison of Hordeum bulbosum-mediated haploid production efficiency in barley using in vitro floret and tiller culture. Theor. Appl. Genet. 77:701-704.

Churchill, G.A., and R.W. Doerge. 1994. Empirical threshold values for quantitative trait mapping. Genetics 138:963-971.

Hackett, C.A., R.P. Ellis, B.P. Forster, J.W. McNicol, and M. Macaulay. 1992. Statistical analysis of a linkage experiment in barley involving quantitative trait loci for height and ear-emergence time and 2 genetic markers on chromosome-4. Theor. Appl. Genet. 85:120-126.

Haley, C.S., and S.A. Knott. 1992. A simple regression method for mapping quantitative trait loci in line crosses using flanking markers. Heredity 69:315-324.

Harvey, B.L., and B.G. Rossnagel. 1984. Harrington barley. Can. J. Plant Sci. 64:193-194.

Hayes, P.M., T. Blake, T.H.H. Chen, S. Tragoonrung, F. Chen, A. Pan, and B. Liu. 1993a. Quantitative trait loci on barley (Hordeum vulgare L.) chromosome 7 associated with components of winterhardiness. Genome 36:66-71.

Hayes, P.M., B.H. Liu, S.J. Knapp, F. Chen, B. Jones, T. Blake, J. Franckowiak, D. Rasmusson, M. Sorrells, S.E. Ullrich, D. Wesenberg, and A. Kleinhofs. 1993b. Quantitative trait locus effects and environmental interaction in a sample of North American barley germ plasm. Theor. Appl. Genet. 87:392-401.

Holloway, J.L., and S.J. Knapp. 1994. GMendel 3.0 Users Guide, Oregon State University, Department of Crop and Soil Science, Corvallis.

Jansen, R.C., and P. Stam. 1994. High resolution of quantitative traits into multiple loci via interval mapping. Genetics 136:14471455.

Jensen, J. 1989. Estimation of recombination parameters between a quantitative trait locus (QTL) and two marker gene loci. Theor. Appl. Genet. 78:613-618.

Kasha, K.J., and K.N. Kao. 1970. High frequency haploid production in barley (Hordeum vulgare L.). Nature 225:874-876.

Kasha, K.J., A. Kleinhofs, A. Kilian, M. Saghai Maroof, G.J. Scoles, P.M. Hayes, F.Q. Chen, X. Xia, X.-Z. Li, R.M. Biyashev, D. Hoffman, L. Dahleen, T.K. Blake, B.G. Rossnagel, B.J. Steffenson, P.L. Thomas, D.E. Falk, A. Laroche, W. Kim, S.J. Molnar, and M.E. Sorrells. 1995. The North American barley map on the cross HT and its comparison to the map on cross SM. p. 73-88. In K. Tsunewaki (ed.) The plant genome and plastome: Their structure and evolution. Kodansha Scientific Ltd., Tokyo, Japan.

Kjaer, B., V. Haahr, and J. Jensen. 1991. Associations between 23 quantitative traits and 10 genetic markers in a barley cross. Plant Breed. 106:261-274.

Kleinhofs, A., A. Kilian, M.A. Saghai Maroof, R.M. Biyashev, P. Hayes, F.Q. Chen, N. Lapitan, A. Fenwick, T.K. Blake, V. Kanazin, E. Ananiev, L. Dahleen, D. Kudrna, J. Bollinger, S.J. Knapp, B. Liu, M. Sorrells, M. Heun, J.D. Franckowiak, D Hoffmann, R. Skadsen, and B.J. Steffenson. 1993. A molecular, isozyme and morphological map of barley (Hordeum vulgare) genome. Theor. Appl. Genet. 86:705-712.

Knapp, S.J., and W.C. Bridges. 1990. Using molecular markers to estimate quantitative trait locus parameters: power and genetic variances for unreplicated and replicated progeny. Genetics 126: 769-777.

Lander, E.S., and D. Botstein. 1989. Mapping mendelian factors underlying quantitative traits using RFLP linkage maps. Genetics 121:185-199.

Laurie, D.A., N. Pratchett, J.H. Bezant, and J.W. Snape. 1995. RFLP mapping of five major genes and eight quantitative trait loci controlling flower time in a winter $\times$ spring barley (Hordeum vulgare L.) cross. Genome 38:575-585.

Powell, W., R.P. Ellis, M. Macaulay, J. McNicol, and B.P. Forster. 1990a. The effect of selection for protein and isozyme loci on quantitative traits in a doubled haploid population of barley. Heredity $65: 115-122$.

Powell, W., R.P. Ellis, and W.T.B. Thomas. 1990b. The effects of major genes on quantitatively varying characters in barley. III. The 2 Row 6 Row Locus (V-v). Heredity 65:259-264.

Shepherd, K.W., and A.K.M.R. Islam. 1992. Progress in the production of wheat-barley lines. p. 99-114. In P.R. Shewry (ed.) Barley: Genetics, biochemistry, molecular biology and biotechnology. C.A.B. International, Wallingford, UK.

Robertson, D.S. 1985. A possible technique for isolating genic DNA for quantitative traits in plants. J. Theor. Biol. 117:1-10.

Thomas, W.T.B., W. Powell, and J.S. Swanston. 1991. The effects of major genes on quantitatively varying characters in barley. 4 . The GPert and denso loci and quality characters. Heredity 66: 381-389.

Thomas, W.T.B., W. Powell, R. Waugh, K.J. Chalmers, U.M. Barua, P. Jack, V. Lea, B.P. Forster, J.S. Swanston, R.P. Ellis, P.R. Hanson, and R.C.M. Lance. 1995. Detection of quantitative trait loci for agronomic, yield, grain and disease characters in spring barley (Hordeum vulgare L.). Theor. Appl. Genet. 91: $1037-1047$.

Tinker, N.A., and D.E. Mather. 1995a. Methods for QTL analysis with progeny replicated in multiple environments. J. Quantitative Trait Loci (http://probe.nalusda.gov:8000/otherdocs/jqtl/1).

Tinker, N.A., and D.E. Mather. 1995b. MQTL: software for simplified composite interval mapping of QTL in multiple environments. J. Quantitative Trait Loci (http://probe.nalusda.gov:8000/otherdocs/jqtl $/ 2$ ).

Zeng, Z-B. 1994. Precision mapping of quantitative trait loci. Genetics 136:1457-1468. 